\title{
O papel da Universidade no contexto da política de Educação Inclusiva: reflexões sobre a formação de recursos humanos e a produção de conhecimento
}

\author{
Rosana Glat* \\ Márcia Denise Pletsch**
}

\section{Resumo}

O presente texto objetiva discutir e apresentar, de forma sucinta, linhas de ação sobre o papel da Universidade na promoção do desenvolvimento psicossocial e educacional de pessoas com deficiências e outras necessidades especiais. Tomando como referência a literatura especializada, aborda questões voltadas para a formação de recursos humanos, sobretudo a formação de professores e a produção de conhecimento na área de Educação Especial, adquirido por meio de pesquisas e projetos de extensão, realizados, preferencialmente, em parceria com os agentes educacionais que atuam no campo. Analisa ainda, como essas ações podem influenciar na efetivação das políticas voltadas para a inclusão escolar, laboral, e social da população com deficiências e demais transtornos do desenvolvimento.

Palavras-chave: Inclusão escolar e laboral; Formação de professores; produção de conhecimento.

\section{The role of the University in the context of Inclusive Education Policy: reflections about human resources formation and knowledge production}

\begin{abstract}
The present text aims to discuss and present, briefly action lines about the role of University in the promotion of psicossocial and educational development of people with handicap and other special needs. Taking the framework of specialized literature, it brings different questions dealing with human resources formation, specially, teacher formation, and the production of knowledge in the area of Special Education, obtained through research and extension projects, done, preferentially, in partnership with the educational agents that work in the field. It also analyses how these actions may influence the implementation of policies regarding school, labor, and social inclusion of people with handicap and other developmental disorders.
\end{abstract}

Keywords: School and labor inclusion; Teacher training; Knowledge production.

\footnotetext{
* Professora Doutora da Universidade do Estado do Rio de Janeiro e atualmente vice-coordenadora do Programa de Pós-Graduação em Educação. Rio de Janeiro, Brasil.

** Professora Doutora do Instituto Multidisciplinar e do Programa de Pós-Graduação em Educação, Contextos Contemporâneos e Demandas Populares da Universidade Federal Rural do Rio de Janeiro (UFRRJ). Rio de Janeiro, Brasil.
} 


\section{O papel da Universidade no contexto da política de Educação Inclusiva: reflexões sobre a formação de recursos humanos e a produção de conhecimento}

O objetivo do presente texto é discutir algumas linhas de ação sobre o papel da Universidade na promoção do desenvolvimento psicossocial e educacional de pessoas com deficiências e outras necessidades especiais. Para tal, estaremos abordando questões voltadas para a formação de recursos humanos, sobretudo professores. Também focalizaremos como a produção de conhecimento, adquirido por meio de pesquisas e projetos de extensão, realizados, preferencialmente, em parceria com os agentes educacionais que atuam no campo, pode influenciar na efetivação das políticas voltadas para a inclusão escolar, laboral, e social de modo geral, desta população.

Conforme já pontuado em trabalho anterior (GLAT \& PLETSCH, 2004), a Universidade, a partir de suas três dimensões constitutivas - ensino, pesquisa e extensão - tem uma grande contribuição na operacionalização das políticas de inclusão educacional. Enfatizando nesta área, pode-se considerar esta ação desenvolvendo-se em duas esferas básicas: 1) na formação inicial e continuada de professores e demais agentes educacionais; 2) na produção de conhecimento por meio de projetos de pesquisa e de extensão que validem e disseminem propostas educativas bem sucedidas para atender às novas demandas decorrentes da politica educacional e reivindicações sociais.

A vocação primária da universidade é o ensino: a formação de recursos humanos; e no caso das faculdades ou departamentos de Educação, a formação de professores. Este é, sem dúvida, o aspecto determinante para a efetivação de uma política de inclusão e disseminação de propostas educacionais que, de fato, contribuam com o processo ensino aprendizagem de alunos com deficiências e outras condições atípicas de desenvolvimento (FONTES, 2007; OLIVEIRA \& SANTOS, 2009; MARTINES, 2009; BRAUN, 2010).

É sabido que as políticas públicas em vigor cada vez mais privilegiam a inclusão de alunos com necessidades educacionais especiais no ensino regular, o que vem levando, em certa medida a uma fragilidade e descontinuidade das propostas realizadas em escolas e classes especiais (BRASIL, 2008; 2009). No entanto, a implementação desta política não é simples. Além de considerações de ordem estrutural (SOARES, 2010) vem sendo exaustivamente demonstrado que a principal barreira para inclusão escolar é o despreparo dos professores e demais agentes educacionais, que não estão capacitados para lidar com alunos com significativos déficits cognitivos, psicomotores e/ou sensoriais na complexidade cotidiana de uma classe comum. Estas constituem-se de turmas com mais de 30 alunos, muitos dos quais que sem ter nenhum diagnóstico também apresentam sérios problemas de comportamento e/ou aprendizagem (GLAT \& NOGUEIRA, 2002; GLAT \& BLANCO, 2007; SANTOS, 2010). Como conseqüência, grande parte desses alunos está matriculada e freqüentando classes comuns, porém sem participar efetivamente nas atividades escolares cotidi- 
anas e sem desenvolver conhecimentos sociais e acadêmicos necessários para viver de forma independente e autônoma (REDIG, 2010; BURKLE, 2010; GLAT, 2010).

É preciso ressaltar, entretanto, que a precária formação não afeta somente aqueles que atuam no ensino regular, mas também os professores especializados. Estes, como bem lembra Bueno (1999), vêm construindo sua competência com base no conhecimento das dificuldades específicas do alunado que atendem, dando ênfase à diminuição ou compensação dos efeitos de suas deficiências. Acrescenta-se a isso o fato de que esses docentes trabalham em situações, quase que individualizadas, em pequenos grupos, nas classes especiais com uma dinâmica e racionalidade própria, a qual, muitas vezes é estruturada sem um planejamento consistente e uma proposta de avaliação sistemática (GLAT \& BLANCO, 2007; FONTES, 2007), o que certamente acarreta em prejuízos no desenvolvimento dos sujeitos que frequentam esses espaços.

De fato, o baixo nível de aprendizagem e desenvolvimento acadêmico de alunos de classes ou escolas especiais tem sido um dos argumentos utilizados para a descontinuidade destes serviços. Não se pode negar que é comum observamos alunos, sobretudo com deficiência intelectual, que passaram anos e anos no ensino especial sem adquirir noções básicas de aritmética, sem saber ver horas, usar dinheiro, nem tampouco desenvolveram conceitos básicos presentes na alfabetização funcional. Diversos estudos vêm mostrando o pouco impacto das escolas e classes especiais no processo de inclusão escolar e social de alunos com deficiências, sobretudo na área cognitiva, ressaltando o caráter segregador e excludente desses espaços (FERREIRA, 1989; NUNES \& FERREIRA, 1993; ABRANTES, 1997, DE CARLO, 2001; SCHEINDER, 2003; AMARAL, 2004; SANTOS, 2006).

A falta de escolarização e desenvolvimento de conceitos básicos necessários para viver uma vida autônoma impedem muitos alunos com deficiências, sobretudo intelectual e ou transtornos do desenvolvimento (como autismo) de ingressarem no mercado de trabalho ou terem uma vida adulta mais significativa existencialmente. De fato, a escola, seja regular ou especializada, em nosso país, de modo geral, não tem preparado esses alunos nas habilidades sociais básicas as quais são pré-requisitos para ingresso no mercado de trabaIho, mesmo informal.

Ainda sobre este aspecto, há uma carência no Brasil de profissionais qualificados que promovam e auxiliem o processo de inclusão laboral desta população. Mesmo quando há empresas interessadas em empregar pessoas com deficiências, seus departamentos de recursos humanos, por um lado, e os agentes vocacionais de instituições especializadas ou até mesmo os órgãos públicos responsáveis como, por exemplo, as secretarias de educação ou dos direitos das pessoas com deficiências, por outro, não estão preparados para empreender as estratégias, treinamento e adaptações necessárias para efetivar este processo. 
Em suma, os professores do ensino regular não estão capacitados para trabalhar com alunos com deficiências por um lado, e por outro, os professores especialistas também tem sua prática reduzida a condições especiais, e não tem experiência de atuação em situação inclusiva. Uma formação (inicial e continuada) dos professores voltada para essa proposta, portanto, é uma das medidas mais urgentes para a efetivação das políticas de inclusão escolar (BUENO, 1999; FONTES, 2007; PLETSCH \& GLAT, 2007; PLETSCH, 2010).

Um outro fator que dificulta a inclusão escolar relaciona-se ao afastamento histórico entre Educação Especial e Educação Regular. Assim, apesar do fato de que as classes especiais estão inseridas em escolas regulares, via de regra, não consideradas no projeto político-pedagógico da escola, e os próprios professores são considerados profissionais a parte do sistema (MULLER \& GLAT, 1999; REDIG, 2010). Problema semelhante ocorre com professores especializados de salas de recursos e itinerantes, que nem sempre têm condições de trabalhar de forma integrada com os professores das classes regulares onde seus alunos estão inseridos. Entre outras razões, porque atendem um grande número de alunos de diferentes escolas, às vezes muito distantes umas das outras (BURKLE, 2010; PLETSCH, 2010; PLETSCH \& GLAT, 2007; REDIG, 2010).

Retomando a questão da capacitação docente, é preciso lembrar que a precariedade da formação de professores não se restringe ao atendimento a alunos com necessidades especiais. De fato, esta tem sido uma preocupação constante do Ministério da Educação. De acordo com a Lei de Diretrizes e Bases da Educação (BRASIL, 1996), a formação inicial dos professores deverá ser realizada preferencialmente em universidades ou institutos superiores de Educação. No entanto, continua admitindo a formação mínima em curso normal para a atuação na educação infantil e nos anos iniciais do ensino fundamental. ${ }^{1}$

No que se refere, especificadamente, à formação de professores para atender a política de inclusão, o Ministério da Educação já vem há muito apontando a necessidade de incorporar conteúdos sobre necessidades educacionais especiais em todos os cursos de graduação, principalmente na área da formação de professores, tanto Pedagogia com demais Licenciaturas (BRASIL, 1994; 1999; 2002).

No entanto, ainda são raros os cursos de licenciatura, e mesmo de Pedagogia, que oferecem habilitação ou disciplinas voltadas às especificidades de alunos com necessidades educacionais. E pouca ênfase é dada, mesmo em cursos com reformulações curriculares recentes, para o estudo do processo ensino aprendizagem e inclusão escolar destes alunos como fenômeno complexo e atual, concernente a todos os professores e ao sistema escolar. Vale ressaltar que esta demanda não se restringe aos cursos de formação de professores. Outras áreas como Medicina, Psicologia, Fisioterapia, Arquitetura, Desenho Industrial, etc, carecem de capacitar melhor os futuros profissionais para atender às demandas de uma sociedade inclusiva. 
Essa é uma questão bastante preocupante, uma vez que o processo de inclusão escolar está sendo gradativamente (às vezes, bruscamente) implementado em todo o país, a composição do alunado das escolas se tornando cada vez mais diversificada, e o currículo dos cursos de formação de professores, de modo geral, não contempla essa nova realidade. O mesmo pode-se dizer no âmbito da inclusão social e profissional. Pessoas com deficiências e suas famílias estão mais conscientes de seus desejos e possibilidades, há toda uma legislação que ampara esse processo, há demanda das empresas, e não temos pessoal qualificado - nem sendo qualificado nas universidades para atuar nesta nova realidade. Em outras palavras, o currículo da maioria cursos universitários brasileiros não tem a inclusão social como norte; em conseqüência, os futuros docentes continuarão despreparados para atuar sob novo paradigma da sociedade aberta à diversidade, resultando em prejuízo social e acadêmico aos alunos com deficiências e outras necessidades especiais. ${ }^{1}$

De acordo com Bueno (1999), para fazer frente a esta realidade as universidades precisam ser capazes de formar dois tipos de educadores: a) professores do ensino regular que sejam capacitados com um mínimo de conhecimento e prática sobre o alunado diversificado, contemplados nas licenciaturas em geral; b) e professores "especialistas" das diferentes necessidades educacionais especiais, a nível de especialização ou complementação por meio de habilitações nas faculdades ou departamentos de Educação. Estes seriam preparados para atuar no atendimento educacional especializado direto à essa população (em classes especiais, salas de recursos ou salas de recursos multifuncionais, ou atendimento individualizado), na supervisão, orientação e suporte aos professores do ensino regular, bem como na gestão de sistemas educacionais visando a inclusão. Em nossa opinião com a implementação em todo o país da modalidade de Atendimento Educacional Especializado ${ }^{3}$ a formação de especialistas torna-se ainda mais urgente. O mesmo poderia ser aplicado para as demais áreas, como, por exemplo, psicólogos, fonodiólogos, entre outros profissionais que possam atuar com pessoas com alguma deficiência.

O grande desafio posto para as universidades é formar profissionais / educadores que não sejam apenas instrumentos de transmissão de conhecimentos, mas, sobretudo, de novas atitudes e práticas que valorizem a diversidade humana. Neste sentido devem ser preparados para construir estratégias de ensino e adaptar atividades e conteúdos que permitam a aprendizagem e desenvolvimento de todos os alunos. Cabe às faculdades de Educação, também, trabalhar com a formação continuada dos atuais professores, e incentivar o vínculo direto entre os professores da Educação Especial e do Ensino Regular, através de discussões nas disciplinas, trabalhos de campo, estágios, entre outras ações.

Vale ressaltar que, talvez por conta das atuais políticas educacionais, vem sendo criada uma falsa dicotomia entre Educação Inclusiva e Educação Especial, como se o advento de uma representasse a descontinuidade da outra (GLAT \& BLANCO, 2007; PLETSCH, 2010; MENDES 2010). Na realidade, en- 
tretanto, ocorre justamente o contrário. Em um sistema educacional inclusivo torna-se fundamental a especificidade da experiência em processos diferenciais de aprendizagem da Educação Especial, tanto como campo de conhecimento quanto como área de atuação aplicada (GLAT \& BLANCO, 2007). E aí, mais uma vez, fica claro a importância do papel da universidade em manter o desenvolvimento desta área. Autores como Ainscow (2004), Liberman (2003) e Beyer (2008) reforçam nossos argumentos.

De acordo com Ainscow (2004) a formação de professores advindos na área de Educação Especial — com seus conhecimentos, métodos e recursos construídos ao longo de décadas - é de grande importância para dar suporte aos professores do ensino regular no processo de inclusão. Nessa direção Pletsch (2010) com base em Liberman (2003), chama atenção para as mudanças necessárias a serem realizadas nas práticas desenvolvidas pela Educação Especial para que se estruturem ao processo de ensino dos alunos com alguma deficiência, não como "reforço pedagógico" como vem sendo observado, mas como uma alternativa articulada ao ensino comum, lançando mão de recursos e métodos para um efetivo processo de ensino-aprendizagem.

Beyer (2008, p. 78) segue na mesma direção ao assinalar que é um equívoco "simplesmente 'importar' a Educação Especial para a educação inclusiva, sem revisões teórico-instrumentais. (...) também é um equívoco ignorar ou romper com o acervo histórico da Educação Especial". Com base nessa análise, nos apresenta o conceito de Educação Especial subsidiária ou móvel que, em suas palavras, "significa a transposição sistêmica e conceitual da Educação Especial, dos redutos históricos de sua atuação (escolas e classes especiais, instituições especializadas, clínicas, etc), para uma atuação pedagógica conjugada com os educadores e professores das escolas do ensino comum" (BEYER, 2008, p. 83). Tomando como referência essa concepção, o autor defende o uso dos recursos e conhecimentos historicamente produzidos há décadas pela Educação Especial na escola comum.

Em outras palavras, sujeitos com necessidades educacionais especiais, sobretudo aqueles que apresentam condições orgânicas que afetam diretamente a aprendizagem (por exemplo, deficiência intelectual ou múltiplas deficiências), só vão poder se beneficiar efetivamente do ensino regular com um sistema de suporte especializado para Ihes apoiar e a seus professores. Por isso, a importância da Universidade manter linhas de ação voltadas para a formação de professores especialistas, tanto em âmbito de formação inicial, quanto continuada.

A segunda esfera de atuação da universidade é a produção de conhecimento, ou seja, a pesquisa. Aárea da Educação, por tradição, tem privilegiado as chamadas pesquisas aplicadas, cujos resultados podem contribuir diretamente na transformação da realidade. Nesse aspecto, as universidades brasileiras vêm acumulando um significativo acervo de trabalhos científicos sobre inclusão educacional e social de pessoas com deficiências e outras necessidades 
especiais, abrangendo diversas dimensões - formação de professores, ensinoaprendizagem, atitudes e percepções de familiares e profissionais, auto-percepção, profissionalização, políticas públicas, entre tantas outras. Tal material oferece dados importantes sobre o processo de inclusão e as necessidades enfrentadas pelo sistema educacional brasileiro para sua implementação (NUNES, GLAT, FERREIRA \& MENDES, 1998, 2004).

No entanto, (ANACHE, 2007; ANTUNES, BRAUN, MACHADO \& GLAT, 2010; PLETSCH, 2010), ainda são poucos os estudos, experiências e práticas educacionais validadas cientificamente que mostram como ensinar e o que fazer para incluir na escola e no trabalho alunos com deficiências, sobretudo na esfera cognitiva. Em face desta constatação é preciso ampliar o foco das pesquisas em duas direções básicas (GLAT \&PLETSCH, 2004), a saber.

a) Na avaliação das inúmeras experiências ensino para alunos com deficiências em curso, apreciando diferentes condições de aprendizagem, seja individualmente ou em grupos, e abordando tanto as escolas /instituições / classes especiais, quanto turmas inclusivas. A partir de pesquisas de camposob diferentes enfoques ou metodologias, tais como Etnografia, História de Vida, Estudos de Caso, etc. -, será possível identificar, por exemplo, as dificuldades que foram encontradas na prática do dia-a-dia, qual a trajetória (em termos longitudinais) de aprendizagem desses alunos e, principalmente, que estratégias de superação foram encontradas.

b) Na valorização da pesquisa-ação, metodologia voltada à transformação de uma situação do campo. Neste contexto inserem-se o desenvolvimento de métodos e técnicas inovadoras que possam ser levadas a cabo no próprio espaço escolar ou laboral. Ou seja, investigar e experimentar formas inovadoras para promover a aprendizagem e inclusão social no cotidiano.

E aqui a parceria com o campo é primordial, pois o pesquisador representante da academia - não é o detentor do conhecimento e, justamente por isso é que ele pesquisa. Portanto, não pode entrar em uma escola ou outro espaço social com um proposta fechada, pronta para ser aplicada. Qualquer projeto de pesquisa-ação, somente pode se efetivar através da parceria direta com os membros da comunidade em investigação. E através da ação investigativa conjunta entre pesquisador e os sujeitos do campo em estudo que será possível construir uma teoria aplicável àquela realidade particular.

Investir nessas duas direções permite também superar uma outra falsa dicotomia, também muito difundida: da teoria vs. prática ou academia vs. campo. Esta fragmentação é decorrente de uma visão equivocada de que cabe à universidade o papel do pesquisador, do "detentor absoluto" do conhecimento, enquanto que a escola e os professores, por exemplo, figuram tão-somente como sujeitos passivos - objetos de estudo - nesse processo. Ao contrário, o que se propõe é um tipo de integração da universidade com a rede escolar (seja especial ou regular) em que os professores participem ativamente de to- 
das as fases do desenvolvimento do estudo, aprendendo a serem pesquisadores de sua própria prática.

Esta concepção de pesquisa aplicada articula-se ao primeiro aspecto da discussão aqui travada, ou seja, que a formação de educadores e demais profissionais pela universidade deve incluir não apenas um conteúdo abrangente, mas, também, uma maior interrelação com a prática do seu corpo discente, No caso da Pedagogia, em grande medida, o corpo estudantil já é composto por professores que podem desenvolver essas pesquisas em seus próprios locais de trabalho.

E finalmente, o terceiro eixo constitutivo da universidade é a extensão, vinculada intimamente ao ensino e à pesquisa, porém, voltada diretamente para responder às demandas da sociedade. A Extensão projeta-se como um processo de inserção social consciente da universidade que implica em uma retroalimentação mútua entre a produção de conhecimento acadêmico e sua disseminação e concretização em práticas sociais. É na dimensão da extensão que se faz a tão necessária relação teoria-prática, que se manifesta em diversas formas: cursos, capacitações, seminários, consultorias, projetos aplicados e outros projetos desenvolvidos pela universidade em diferentes comunidades.

Cabe destacar, no entanto, que mesmo que freqüentemente as ações extensionistas surjam a partir de demandas sociais específicas, na nossa concepção, extensão universitária (sobretudo no caso das universidades públicas) não é equivalente à prestação de serviços, nem tem como prioridade a captação de recursos, embora muitas vezes esses projetos revertam em verbas para a universidade. Projetos de extensão devem ser diretamente vinculados ao currículo tendo o valor acadêmico como norte e o ensino e a produção de conhecimento como matriz principal (PLETSCH \& GLAT, 2007).

Entretanto, em que pese a disponibilidade da universidade para ir a campo assessorar as escolas, empresas ou outros espaços sociais, precisamos ter a humildade de reconhecer que nós não temos todas as respostas. Temos sim, recursos humanos, metodologia investigativa, e o interesse em analisar o que já está sendo feito para buscar as respostas educativas mais eficazes. No entanto, para que isso aconteça, como já comentado, é fundamental que haja um estreito laço entre a universidade e as demais instituições sociais e comunitárias sociedade, através de convênios, acordos de cooperação e projetos interinstitucionais com as agencias de fomento.

Em fim, o papel e responsabilidade social da universidade, principalmente da universidade pública, se afirmará na produção de conhecimento para a formulação e o debate crítico sobre as políticas educacionais, na formação de educadores e demais profissionais e na criação de parcerias e iniciativas inovadoras com a comunidade. 


\section{Referências}

ABRANTES, A. A. Aluno excluído do sistema público de ensino: a identidade em construção. Dissertação de Mestrado, Pontifícia Universidades Católica de S. Paulo, S. Paulo, 1997.

AMARAL, T. P. do. Deficiência mental leve: processos de escolarização e de subjetivação. Tese (Doutorado em Psicologia), Universidade de São Paulo, 2004.

AINSCOW, M. Hacia uma educación para todos: algumas formas posibles de avanzar. Disponível em: www.inclusioneducativa.cl/docuemtnos. Publicado em 2001. Acesso em: 12 abr. 2004.

ANACHE, A. A.; MITJÁNS, A. M. Deficiência mental e produção científica na base de dados da CAPES: o lugar da aprendizagem. In: Revista Psicologia Escolar e Educacional, v. 11, n. 2, Campinas, p. 253- 274, 2007.

ANTUNES, K. C. V.; BRAUN, P; MACHADO, K. S. \& GLAT, R. Uma análise da produção científica sobre deficiência intelectual na base de dados Scielo: o processo de ensino aprendizagem em foco. IV Congresso Brasileiro de Educação Especial, UFSCar, 2010.

BRASIL. Portaria n. 1793. Brasília, 1994.

. Lei Federal n. 9394/96 de 20 de dezembro de 1996, Estabelece as Diretrizes e Bases da Educação Nacional. Diário Oficial da União, v. 134, n. 248, 22 de dez. de 1996.

. Decreto n. 3298. Brasília, 1999.

. Resolução $\mathbf{n} .1$ que dispõem sobre as Diretrizes Curriculares Nacionais para Formação de Professores em Educação Básica. Brasília, 2002

Política Nacional da Educação Especial na Perspectiva da Educação Inclusiva. Brasília, 2008.

Diretrizes Operacionais do Atendimento Educacional Especializado na Educação Básica, modalidade Educação Especial. Brasília, 2009.

BEYER, H. O. O projeto político-pedagógico da educação inclusiva e a gestão educacional: reflexões com a área de Educação Especial da Secretaria de Educação do Estado do Rio Grande do Sul. In: FREITAS, S. N. (Orgs.). Tendências contemporâneas de inclusão, Editora da UFSM, Santa Maria, p. 77-90, 2008.

BUENO, J. G. Crianças com necessidades educativas especiais, política educacional e a formação de professores: generalistas ou especialistas. Revista Brasileira de Educação Especial, v. 3. n. 5, 7-25, 1999. 
BURKLE, T. S. A sala de recursos como suporte à educação inclusiva no município do Rio de Janeiro: das propostas legais à prática cotidiana. Dissertação de Mestrado, Programa de Pós-Graduação em Educação, Universidade do Estado do Rio de Janeiro (UERJ), Rio de Janeiro, 2010.

BRAUN, P. Formação continuada de professores e o atendimento educacional especializado: solução ou compensação para a escola? In.: Anais do I Seminário sobre o professor da educação inclusiva: humanização do posto de trabalho. Rio de Janiero: NUPI/UERJ, Setembro de 2010.

DE CARLO, Se essa casa fosse nossa...Instituições e processos de imaginação na educação especial. Plexus, São Paulo, 2001.

FERREIRA, J. R. A construção escolar da deficiência mental. 168f. Tese (Doutorado em Educação), Universidade Estadual de Campinas (UNICAMP), 1989.

FONTES, R. de S. O desafio da educação inclusiva no município de Niterói: das propostas oficiais às experiências em sala de aula. 2007. Tese de Doutorado, Programa de Pós-Graduação em Educação, Universidade do Estado do Rio de Janeiro (UERJ), Rio de Janeiro, 2007.

GLAT, R. \& BLANCO, L. de M. V. Educação Especial no contexto de uma Educação Inclusiva. In: GLAT, R. (Org.). Educação Inclusiva: cultura e cotidiano escolar. Editora Sete Letras, p. 15-35, Rio de Janeiro, 2007.

.; \& NOGUEIRA, M. L. de L. Políticas educacionais e a formação de professores para a educação inclusiva no Brasil. In: Revista Integração. Ano 14; Brasília: MEC/SEESP, v. 24, p. 22-27, 2002.

. \& PLETSCH, M. D. O papel da universidade frente às políticas públicas para educação inclusiva. Revista Benjamin Constant, Rio de Janeiro, p. 38,2004

Um estudo etnográfico sobre o cotidiano da inclusão de alunos com necessidades educacionais especiais em escolas da rede regular de ensino. Relatório de Pesquisa CNPq, 2010.

MENDES, E. G. Observatório nacional de educação especial: estudo em rede nacional sobre as salas de recursos multifuncionais nas escolas comuns. Projeto de Pesquisa, 2010.

LIEBERMAN, L. M. Preservar a Educação Especial....para aqueles que dela necessitam. In: CORREIA, L. de M. (Org.). Educação Especial e inclusão: quem disser que uma sobrevive sem a outra não está no seu perfeito juízo. Porto Editora, Porto - Portugal, 2003. (Coleção Educação especial v. 13)

MULLER, T. M. P. \& GLAT, R. Uma professora muito especial. (Questões Atuais em Educação Especial). Editora Sete Letras, Rio de Janeiro, 1999. 
NUNES, L. R. D' O. de P. \& FERREIRA, J. R. Deficiência mental: o que as pesquisas brasileiras têm revelado. In: Em aberto. Brasília. Ano 13, n. 60, Brasília, out./dez., 1993.

. GLAT, R.; FERREIRA, J. R. \& MENDES, E. G. Pesquisa em Educação Especial. (Coleção Questões atuais em Educação Especial, v. III), Rio de Janeiro, Sete Letras, 1998.

FERREIRA, J. R. ; MENDES, E. G. \&; GLAT, R. . O que revelam as teses e dissertações sobre a linguagem e comunicação da pessoa com necessidades especiais?. Temas em Psicologia (Ribeirão Preto), São Paulo, v. 10, n. 1, p. 27-38, 2004.

PLETSCH, M. D. A formação de professores para a educação inclusiva: legislação, diretrizes políticas e resultados de pesquisa. Educar em Revista, Curitiba, n. 33. 2009.

Repensando a inclusão escolar: diretrizes políticas, práticas curriculares e deficiência intelectual. Rio de Janeiro, Editora NAU/EDUR, 2010.

. \& GLAT, R. O ensino itinerante como suporte para a inclusão de pessoas com necessidades educacionais especiais na rede pública de ensino: uma abordagem etnográfica . In: Revista Iberoamericana de Educación, n. 41/2. Disponível em: http://www.rieoei.org/experiencias139.htm? Acesso em: jan. de 2007, p. 1-11.

OLIVEIRA, I. A. de \& SANTOS, T. R. L. dos. Política de educação inclusiva em municípios do estado do Pará: atendimento e formação de professores. In: BAPTISTA, C. R.; JESUS, D. M. (Orgs.). Avanços em políticas de inclusão: o contexto da Educação Especial no Brasil e em outros países. Porto Alegre: Mediação, p. 91-105, 2009.

REDIG, A. Ressignificando a Educação Especial no contexto da Educação Inclusiva: narrativas de professoras especialistas. Dissertação de Mestrado, Programa de Pós-Graduação em Educação, Universidade do Estado do Rio de Janeiro (UERJ), Rio de Janeiro, 2010.

SANTOS, R. A. dos. Processos de escolarização e deficiência: trajetórias escolares singulares de ex-alunos de classe especial para deficientes mentais. 197f, Tese (Doutorado em Educação). Pontifícia Universidade Católica de São Paulo, São Paulo, 2006.

SANTOS, M. L. DO. Permanência dos alunos com necessidades educacionais especiais em classes comuns: a ótica de professores de $5^{\mathrm{a}}$ a $8^{\mathrm{a}}$ séries. Dissertação de Mestrado, Programa de Pós-Graduação em Educação, Universidade de São Paulo, São Paulo, 2010. 
SOARES, M. T. N. Programa Educação Inclusiva Direito à Diversidade: Estudo de caso sobre a estratégia de multiplicação de políticas públicas. Dissertação de Mestrado, Programa de Pós-Graduação em Educação, Universidade Federal da Paraíba, Paraíba, 2010.

SCHNEIDER, D. Alunos excepcionais: um estudo de caso de desvio. In: VELHO, G. (Org.). Desvio e divergência - uma crítica da patologia social. 8. ed., Rio de Janeiro: Jorge Zahar, 2003.

\section{Notas}

${ }^{1}$ Essa deliberação foi confirmada por meio do parecer $n^{0} 1$ do Conselho Nacional de Educação (CNE), aprovado em 19 de fevereiro de 2003, segundo o qual todo professor concursado que atue em turmas de educação infantil ou séries iniciais do ensino fundamental tem assegurado o seu cargo, mesmo que não freqüente curso em nível superior (PLETSCH, 2009).

2 Cabe lembrar que, no Brasil, temos apenas dois cursos de Educação Especial, localizados na Universidade Federal de Santa Maria/RS e na Universidade Federal de São Carlos/SP.

${ }^{3}$ Resolução 4 de 2 de outubro de 2009 que dispõe sobre as Diretrizes Operacionais do Atendimento Educacional Especializado na Educação Básica, modalidade Educação Especial.

\section{Correspondência}

Rosana Glat - Jardim Botânico 356/503. Jardim Botânico, Rio de Janeiro. CEP 22.461-000.

E-mail: rglat@terra.com.br

Recebido em 13 de setembro de 2010

Aprovado em 26 de outubro de 2010 